\title{
FUNÇÃO OSTEOINDUTORA DE FRAGMENTOS ÓSSEOS CONSERVADOS EM GLICERINA A 98\%. ESTUDO EXPERIMENTAL EM RATOS
}

\author{
OSTEOINDUCTION IN BONE FRAGMENTS PRESERVED IN 98\% GLYCERIN. \\ EXPERIMENTAL STUDY IN RATS
}

\author{
Marluce Macedo Cavassani ${ }^{1}$ Julieta Rodini Engrácia de Moraes ${ }^{2}$ João Guilherme Padilha Filho ${ }^{3}$
}

RESUMO

O objetivo do presente trabalho foi o de avaliar a função osteoindutora atribuída aos fragmentos ósseos conservados em glicerina a $98 \%$, por trinta dias, à temperatura ambiente. Esses fragmentos foram obtidos de fêmures e tíbias de ratos doadores. O implante desta matriz óssea foi realizado no tecido subcutâneo e intramuscular de ratos receptores. Análise histopatológica foi realizada no $30^{\circ}, 60^{\circ}$ e $90^{\circ}$ dia após o implante. Aos 30 dias, notou-se resposta osteogênica positiva, inclusive com mielogênese, que aos 60 e 90 dias foram efetivamente concluídas. Nesses períodos, observou-se a presença de fragmentos de matriz óssea calcificada, sugerindo que fossem tecido ósseo neoformado a partir da atividade osteoblástica observada aos 30 dias. Diante desses resultados, concluiu-se que a glicerina é um bom meio para conservação de fragmentos ósseos para uso em enxertos, uma vez que a função osteoindutora foi preservada.

Palavras-chave: osteoindução, glicerina, enxerto ósseo.

\section{SUMMARY}

The purpose of the present study was to evaluate the osteoinduction of $98 \%$ glycerin-preserved bone fragments preserved by 30 days, kept at the room temperature. The bone fragments were obtained from femur and tibia of rats. The bone fragments were implanted in the subcutaneous and intramuscular tissues of these. Histological studies were done at 30, 60 and 90 days post-operatively. Positive osteogenic and myelogenic response could be seen 30 days after implantion, and, were concluded 60 and 90 days. Completely calcified bone matrix fragments were observed in these days, suggesting that this newly formed bone tissue was derived from the osteoblastic activity observed on 30 post-operatively day. The results showed that glycerin is a good medium to preserve bone fragments for grafts use because it seems to keep the osteoinduction activity.
Key words: BMP, osteoinduction, glycerin, bone graft.

\section{INTRODUÇÃO}

O uso de enxertos ósseos está se tornando frequiente na ortopedia veterinária, como método de resolução das fraturas cominutivas, reduzindo significantemente a necessidade de amputação do membro afetado. Nesse contexto, a necessidade de se instituir banco de ossos para animais está aumentando. Os métodos de preservação mais conhecidos, de acordo com a literatura, são congelamento, descalcificação e esterilização pelo óxido de etileno. Recentemente, PINTO JR. (1990) e COSTA (1996) utilizaram, com sucesso, a glicerina a $98 \%$ como meio de preservação de ossos para uso em enxertos. A glicerina desidrata o tecido ósseo substituindo a maior parte da água intracelular, sem alterar a concentração iônica das células, atuando como eficaz protetor da integridade celular (PIGOSSI, 1964). Além disso, age como anti-séptico ante os vários gêneros de microrganismos patogênicos ou não, atuando como bactericida e fungicida, exceto contra formas esporuladas (PIGOSSI, 1967).

A osteoindução é uma das principais propriedades atribuídas aos enxertos ósseos. O termo refere-se ao processo pelo qual as células tronco mesenquimais, presentes no tecido circunjacente ao local do enxerto, são induzidas à diferenciação em

\footnotetext{
${ }^{1}$ Médico Veterinário/Bolsista IC-FAPESP-processo 95/6890-8. FCAV/UNESP.

${ }^{2}$ Professor Assistente, Doutor, Departamento de Patologia Veterinária, FCAVJ/UNESP, Via de Acesso Professor Doutor Paulo Donato Castellane, Km 05, 14870-000, Jaboticabal-SP. E-mail: jrmoraes@ @cav.unesp.br. Autor para correspondência.

${ }^{3}$ Professor Assistente. Doutor, Departamento de Clínica e Cirurgia Veterinária, FCAV/UNESP.
} 
células de linhagem osteogênica (ALEXANDER, 1987). Esse mecanismo está relacionado à atividade da "bone morphogenetic protein" (BMP) (URIST, 1965; BESSHO et al., 1992; YABU et al., 1992; OGAWA et al., 1992; BESSHO \& IZUKA, 1994; HORISAKA et al., 1994) presente na matriz óssea. Todavia, a preservação dessa proteína e de sua atividade osteoindutora em fragmentos ósseos conservados em glicerina é motivo de dúvida.

Neste ensaio, investigou-se a preservação da atividade osteoindutora em fragmentos ósseos de ratos conservados em glicerina a $98 \%$, durante trinta dias e à temperatura ambiente.

\section{MATERIAL E MÉTODO}

Os fragmentos ósseos utilizados para o enxerto foram obtidos de fêmures e tíbias de ratos adultos jovens e saudáveis, pesando entre 200-250g, que foram sacrificados por inalação prolongada de éter. Após a colheita dos ossos, as epífises, os restos musculares e o periósteo foram removidos com auxílio de serra manual e bisturi. Para a remoção da medula óssea foi utilizado pino metálico com rosca sob água corrente. A seguir, os fragmentos ósseos foram imersos em glicerina a $98 \%$ e mantidos à temperatura ambiente, por 30 dias.

Antes do implante, os fragmentos ósseos foram reidratados durante dez minutos em solução fisiológica. A seguir, foram seccionados com cisalha em tamanhos de $3 \mathrm{~mm}^{2}$. Esses fragmentos foram implantados em dois grupos de quatro ratos, machos e adultos, (180 a 250g), sob anestesia inalatória com éter etílico. No grupo 1, uma vez anestesiados, os animais foram colocados em decúbito ventral, tricotomizados e submetidos à anti-sepsia regional com álcool e iodo povidine. A seguir, foi feita incisão de aproximadamente $1,5 \mathrm{~cm}$ sobre a linha média dorsal da região torácica, e depois da divulsão da pele, os fragmentos foram implantados no tecido subcutâneo, em dois pontos paralelos e eqüidistantes à incisão, sendo depositados seis fragmentos de cada lado.

No grupo 2, os animais anestesiados foram posicionados em decúbito lateral esquerdo e o campo operatório foi preparado como no grupo 1 . Foi feita a incisão da pele na face medial da coxa esquerda, com aproximadamente $1,5 \mathrm{~cm}$ de extensão e outra incisão no músculo grácil, onde foram implantados seis fragmentos ósseos.

Os animais de ambos os grupos foram sacrificados após 30, 60 e 90 dias por inalação prolongada de éter, com vistas à colheita de material no local do implante. Esse material foi fixado em solução de Bouin e, posteriormente, lavado com álcool
$70 \%$, contendo $10 \%$ de amônia, para remoção do ácido pícrico presente no fixador. O material foi então desidratado e incluído em parafina. Cortes histológicos de $7 \mu \mathrm{m}$ de espessura foram corados pela hematoxilina-eosina e examinados em microscopia de luz.

\section{RESULTADOS E DISCUSSÃO}

A matriz óssea desmineralizada (MOD), quando implantada no tecido conjuntivo subcutâneo e muscular, desencadeia uma série de reações teciduais, identificáveis histologicamente, que se sucedem em uma seqüência temporal bem definida. Entretanto, os momentos em que cada transformação ocorre e a duração de cada estádio são variáveis. A formação de tecido e medula óssea observada no presente trabalho ocorreu em tempos mais tardios do que os descritos por URBINATI (1978). Segundo a autora, as características histológicas de osteogênese definidas pela grande quantidade de osteoblastos presentes no interior da matriz óssea, trabéculas ósseas neoformadas e tecido hematopoético, que foram observadas no $20^{\circ}$ dia após o implante, neste ensaio somente foram notados aos 30 dias. Essa diferença pode ser atribuída ao fato de que neste ensaio utilizou-se matriz óssea mineralizada (MOM), enquanto URBINATI (1978) usou matriz óssea desmineralizada. Segundo REDDI (1974), a presença de cálcio nos fragmentos ou no pó de osso inibe as transformações cartilaginosa e óssea. URBINATI (1978), utilizando pó de osso contendo $1,2 \%$ de cálcio, verificou que essa quantidade é suficiente para inibir de maneira quase total a formação de cartilagem e osso, mas não a reação fibroblástica. No presente estudo, apesar da utilização de matriz óssea mineralizada (MOM), os resultados revelaram que o processo de osteoindução não foi inibido. Isso pode estar relacionado com a ação da glicerina sobre os fragmentos ósseos implantados, impedindo, possivelmente, que o efeito inibitório do cálcio sobre a condrogênese e a osteogênese possa se estabelecer. Como a glicerina desidrata o tecido ósseo e preserva a concentração iônica das células, mantendo a integridade celular (PIGOSSI, 1964), é possível que também preserve a BMP, mantendo sua função osteoindutora. Assim, 30 dias após o implante intramuscular, a análise histológica revelou a presença de fragmentos ósseos parcialmente rarefeitos e envolvidos por tecido conjuntivo ricamente vascularizado. Nesses fragmentos, havia quantidade significante de osteoclastos, indicando atividade de reabsorção do tecido ósseo, lacunas preenchidas por células indiferenciadas, megacariócitos e outras células do tecido hematopoético e grande número de 
neovasos. Vestígios de calcificação também foram observados. No interior da matriz óssea e no espaço circunjacente aos fragmentos implantados, estavam presentes osteoblastos, indicando início do processo de ossificação, além de trabéculas ósseas neoformadas demostrando atividade osteoblástica e osteogênica.

O implante de fragmentos ósseos no tecido subcutâneo promoveu reação semelhante à descrita anteriormente. Observou-se atividade osteoblástica expressiva e presença de tecido conjuntivo invadindo a matriz óssea, formando arcabouço de vasos e tecido hematopoético nas lacunas. Nas avaliações dos implantes após 60 dias, observou-se tanto nos do tecido subcutâneo como nos do tecido intramuscular, a presença de fragmentos ósseos com áreas de reabsorção, encapsulados por tecido conjuntivo e com vascularização abundante. A esse tempo já não havia sinais de atividade osteoclástica ou osteoblástica .

Com relação aos implantes examinados após 90 dias, tanto no tecido intramuscular como no subcutâneo, observou-se reação semelhante à descrita aos 60 dias. Porém, nesta última observação, os fragmentos ósseos já se apresentavam calcificados.

Os resultados mostraram que, 30 dias após o implante, havia osteogênese e mielogênese, que se apresentaram consolidadas aos 60 e 90 dias. Nesses períodos mais tardios, observavam-se fragmentos ósseos totalmente calcificados. Essa observação sugere que tais fragmentos sejam ossos neoformados a partir da atividade osteoblástica observada aos 30 dias.

MORAES \& MORAES (1993), trabalhando com implante de matriz óssea desmineralizada em tecido intramuscular e subcutâneo de camundongos, observaram, aos 28 dias, reações semelhantes às verificadas aos 30 dias neste ensaio. Entretanto, aqueles autores utilizaram camundongos e MOD, enquanto, neste estudo, foram utilizados ratos e MOM. De acordo com HUGGINS et al. (1970), os camundongos são menos propensos às transformações ósseas do que os ratos. Além disso, no trabalho mencionado, a resposta no tecido subcutâneo ao implante de MOD, que normalmente é rara ou ausente em camundongos, foi estimulada com a aplicação de carragenina ou nistatina. Essas substâncias inflamatórias promoveram o acúmulo de macrófagos na região, os quais parecem estar relacionados ao processo de osteoindução (MORAES \& MORAES, 1993).

Os resultados do presente estudo confirmam os de PINTO JR. (1990) e de COSTA(1996), que utilizaram ossos alógenos preservados em glicerina a $98 \%$ na reparação de fraturas de ossos longos.
Observaram que os cães receptores apresentaram recuperação do membro afetado em $100 \%$ dos casos, concluindo que esse método de preservação também é viável para manutenção da função osteoindutora da matriz óssea. Uma vez que o uso de MOM, apenas conservada a frio, não foi efetivo para indução de osteogênese experimental em ratos, independentemente do local de implante (REDDI, 1974; URBINATI, 1978), os resultados encontrados neste trabalho permitem concluir que a glicerina a $98 \%$ é um bom meio para conservação de fragmentos ósseos destinados a enxertia. Esses, quando implantados no tecido subcutâneo e intramuscular de ratos, induziram a diferenciação de células mesenquimais em tecido ósseo, que completou seu processo de calcificação aos 90 dias. Então, de alguma maneira, a glicerina preservou a função osteoindutora do material implantado, quiçá por conferir algum tipo de proteção à BMP.

A evidência da preservação da atividade osteogênica de fragmentos ósseos pela glicerina possibilita que bancos de ossos destinados à enxertia estoquem fragmentos de MOM ou MOD em lugar de peças íntegras e grandes, otimizando a utilização de espaço de armazenamento e a quantidade de glicerina.

\section{AGRADECIMENTOS}

Os autores agradecem à FAPESP, pelo concessão de bolsa de IC ( Proc. 95/6890-8), à Srta. Francisca de Assis Ardisson e à Sra. Maria Ines Yamazaki de Campos pelos serviços técnicos prestados.

\section{REFERÊNCIAS BIBLIOGRÁFICAS}

ALEXANDER, J.W. Bone grafting. Veterinary Clinincs of North America Small Animal Practice, v.17, n.4, p.811819, 1987.

BESSHO, K., IZUKA, T. Activit and solubility of bone morphogenetic protein derived from porcine bone matrix. British Journal of Oral \& Maxillofacial Surgery, v.32, p.86-90, 1994.

BESSHO, K., TAGAWA, T., MURATA, M. Comparison of bone matrix-derived bone morphogenetic proteins from various animals. Journal of Oral \& Maxillofacial Surgery, v.50, n.5, p.496-501, 1992.

COSTA, J.L.O. Reconstrução de grande falha óssea com enxerto cortical alógeno conservado em glicerina, fixado com placa e parafusos de aço inoxidável da série 304. Estudo experimental em cães (Canis familiaris). Jaboticabal, 1996. 100p. Dissertação (Mestrado em Medicina Veterinária) - Curso de Pós-graduação em Medicina Veterinária, Faculdade de Ciências Agrárias e Veterinárias, Universidade Estadual Paulista, 1986. 
HORISAKA, Y., OKAMOTO, Y., MATSUMOTO, N., et al. Histological changes of implanted collagen material during bone induction. Journal of Biomedical Material Research, v.28, p.97-103, 1994

HUGGINS, C.B., WISEMAN, S., REDDI, A.H. Transformation of fibroblasts by allogeneic transplants of demineralized tooth and bone. Journal of Experimental Medicine, v.132, p.1250-1258, 1970.

MORAES, J.R.E., MORAES, F.R. Effect of a persistent inflammatory process on experimental heterotopic ossification. The influence of macrophages. Brazilian Journal of Medical and Biological Research, v.26, p.53-66, 1993.

OGAWA, Y., SCHMIDT, D.K., NATHAN, R.M., et al. Bovine bone activin enhances bone morphogenetic protein-induced ectopic bone formation. Journal of Biological Chemistry, v.267, p.14233-14237, 1992

PIGOSSI, N. Implantação de dura-máter homóloga conservada em glicerina. Estudo experimental em cães. São Paulo, 1964. 92p. Tese (Doutorado em Cirurgia) - Faculdade de Medicina, Universidade de São Paulo, 1964.

PIGOSSI, N. Glicerina na conservação de dura-máter. Estudo experimental. São Paulo, 1967. 83p. Tese (Livre docência- em Cirurgia) - Faculdade de Medicina, Universidade de São Paulo. 1967.

PINTO JR., H.S. Utilização de enxertos ósseos homólogos preservados na reparação de fraturas cominutivas de ossos longos em cães. São Paulo, 1990. 37p. Dissertação (Mestrado em Cirurgia Veterinária) - Faculdade de Medicina Veterinária e Zootecnia, Universidade de São Paulo, 1990.

REDDI, A.H. Bone matrix in the solid state: geometric influence on diferenciation of fibroblasts. Advances in Biology and. Medical Physiology, v.15, p.1-18, 1974.

URBINATI, E.C. Condrogênese e osteogênese: indução por pó de osso descalcificado. Ribeirão Preto, 1978. 44p. Dissertação (Mestrado em Morfologia-Biologia Celular) - Faculdade de Medicina de Ribeirão Preto, Universidade de São Paulo, 1978

URIST, M.R. Bone: formation by autoinduction. Science, v.150, p.893-899, 1965

YABU, M., TAKAOKA, K., HASHIMOTO, J., $\boldsymbol{e}$ t $\boldsymbol{a l}$. Immunohistochemical, autoradiografic and electron microscopic studies on the transformation of fibroblasts into condrocytes in the mouse subfascia induced by bone morphogenetic protein. Histochemistry, v.97, p.463-468, 1992.

Ciência Rural, v. 31, n. 3, 2001. 